\title{
ADVANCED OXIDATION TREATMENTS OF OLIVE MILL WASTEWATER
}

\author{
Mia Ivanov ${ }^{1}$, Katarina Perić ${ }^{1}$, Tomislava Vukušić ${ }^{1 *}$, Tea Štefanac ${ }^{1}$, Višnja Stulić ${ }^{1}$, Klara Kraljić $^{1}$, \\ Goran Smoljanić², Tibela Landeka Dragičević ${ }^{1}$, Zoran Herceg ${ }^{1}$ \\ ${ }^{I}$ Faculty of Food Technology and Biotechnology, Pierottijeva 6, Zagreb \\ ${ }^{2}$ Faculty of Mechanical Engineering and Naval Architecture, Ivana Lučića 5, Zagreb \\ *E-mail of corresponding author: tvukusic@pbf.hr
}

\begin{abstract}
New and innovative advanced oxidative processes for wastewater treatments are currently in the focus of scientific research and development for possible industrial implantation. The main aim of this study was to investigate the effect of cold plasma treatment, high intensity ultrasound and UV radiation with the addition of additives: $\mathrm{H}_{2} \mathrm{O}_{2}, \mathrm{TiO}_{2}, \mathrm{FeCl}_{3} \times 6 \mathrm{H}_{2} \mathrm{O}$ on degradation and removal of complex organic compounds from olive mill wastewater (OMWW). Olive mill wastewater represents a potential ecological problem when it is raw disposed into the environment, because of its high organic load. OMWW samples (with and without additives) were treated by high-voltage plasma discharge at frequencies $60 \mathrm{~Hz}$ and 120 $\mathrm{Hz}$ in combination with pumped gases (nitrogen, air and oxygen) for 30 minutes, by UV radiation for 30 minutes and 10 minutes by high intensity ultrasound. Physico-chemical parameters of quality, chemical oxygen demand (COD), and total dissolved carbon (TOC) were determined. The results have shown the efficacy of plasma treatment in degradation of organic compounds as well as degradation and reduction of polyphenolic compounds. Reduction of colour and total dissolved carbon occurred in all treated samples, mostly with the addition of $\mathrm{FeCl}_{3} \times 6 \mathrm{H}_{2} \mathrm{O}$. Treatment with $U \mathrm{~V}$ radiation and ultrasound proved to be the most efficient resulting in the 50\% reduction of organic compounds after a 10-minute treatment.
\end{abstract} Keywords: wastewater, cold plasma, OMWW, ultrasound, UV radiation

\begin{tabular}{c}
\hline $\begin{array}{c}\text { Received: 01.07.2019. / Accepted: 18.11.2019. } \\
\text { Published online: 09.12.2019. }\end{array}$ \\
Original scientific paper
\end{tabular}

\section{INTRODUCTION}

The food industry is a large consumer of water but also acts as one of the biggest generators of wastewater. Olive mill wastewater (OMWW) is one of the most loaded and complex agro-industrial wastewater with hardly biodegradable constituents and it is necessary to process it prior to discharge into the aquatic environment or the public drainage system.

OMWW is a mixture of vegetation water, soft tissue from olive fruit and water used in various stages of oil pressing process; water added during centrifugation, water from filters and water from the washing equipment. It contains olive fruit pulp, pectin, oil, and other substances suspended in a relatively stable emulsion. According to its physico-chemical characteristics olive mill wastewater is a dark coloured liquid characterized by expressed odour, high organic loads (Chemical oxygen demand (COD) from 47-178 $\mathrm{gO}_{2}$ $\left.\mathrm{L}^{3}\right)$, high concentration of phenols $\left(0,5-0,7 \mathrm{gL}^{-3}\right)$, low $\mathrm{pH}(\mathrm{pH}=4-5)$, high conductivity $\left(5,50-10 \mathrm{dSm}^{-1}\right)$ and high ratio of suspended particles (to $20 \mathrm{gL}^{-1}$ ) (Paredes et al. 1997; Akar et al. 2009; Morillo et al. 2009).

OMWW contains organic compounds such as soluble phenols (hydroxytyrosol, tyrosol, catechol, methylcatechol, caffeic acid, vanillic acid, p-coumaric acid, etc.), polyphenols, polyalcohols, sugars, tannins, lipids, and pectins originally from olives (Tsagaraki et al. 2007). In addition, several studies have shown that phenolic compounds are responsible for the phytotoxicity of OMWW (Niaounakis \& Halvadakis 2006; Quaratino et al. 2007; Kallel et al. 2009). It has been established that organic loads, especially phenolic compounds, inhibit the efficacy of anaerobic digestion and therefore, in some cases, advanced oxidation methods are considered to be an extraordinary alternative (Kallel et al. 2009).

Due to the diversity of potential contaminants in OMWW and the problem of their removal, research is directed towards the development of new technologies, and the current emphasis of the research is on reducing the harm and toxicity of advanced oxidation processes (AOPs) that have proven to be exceptionally high performance for removing highly degradable compounds.

AOPs are defined as processes based on the formation of various oxidation agents in sufficient quantity for complete mineralization of organic substances. The main mechanism of AOP is to generate highly reactive free radicals that effectively react with carbon-carbon double bonds and attack the aromatic nucleus (Zaviska et al. 2009). AOP includes: chemical processes $\left(\mathrm{O}_{3}, \mathrm{O}_{3} / \mathrm{H}_{2} \mathrm{O}_{2}, \mathrm{Fe}^{3+} / \mathrm{H}_{2} \mathrm{O}_{2}\right)$ (Nesheiwat \& Swanson, 2000), mechanical processes (cavitation generated by ultrasonic radiation or using compression such as valves or openings in hydraulic devices) (Adewuyi 2001), photochemical or photocatalytic processes (by 
ultraviolet radiation in the presence of oxidants or catalysts) (Bhatkhande et al. 2002) and electrical processes ("corona" discharge or "glow" discharge). The resulting hydroxyl radicals are strong oxidation reagents with a $2.33 \mathrm{~V}$ oxidation potential and show very rapid oxidation reactions compared to conventional oxidants such as hydrogen peroxide or $\mathrm{KMnO}_{4}$ (Gogate et al. 2004).

\subsection{Cold plasma}

Plasma coming from the Greek word "plasma" in free translation means self-forming material (MottSmith \& Langmuir 1926). It consists of positive and negative ions, free radicals, gas atoms, molecules, electrons and neutral particles (Roya \& Hosseini 2014). The term "plasma" was first used in 1928 by Irving Langmuir to define the fourth state of the substance with partial or completely ionized gas status. Changing the phase of a solid, liquid and gaseous state is generated by increasing the energy intake and also the further increase of energy above a certain level in the gaseous phase causes the ionization of molecules resulting in plasma formation (Thirumdas et al. 2014). Plasma can be created by subjecting the gas to the electric field (between the two electrodes) of a constant or changed high frequency amplitude. Applied energy can be from a variety of sources (thermal, electrical, magnetic), causing an increase in kinetic energy of the electron, resulting in increased collisions with neutral molecules and plasma formation, divided into two major categories - thermal and non-thermal plasma (Cheng et al. 2007).

Plasma generates oxidizing agents $\mathrm{OH}, \mathrm{O}, \mathrm{H}_{2} \mathrm{O}_{2}$ which have a high oxidative potential for oxidation of organic compounds and purification of water ( $\mathrm{Li}$ et al. 2007). Plasma can be created directly in the liquid, in the air above the liquid, or in the case of a hybrid reactor, both in liquid and in the air. Research has focused on the use of non-thermal plasma for the oxidation of phenols, dyes, degradation of pharmaceutical compounds and pesticides. Non-thermal plasma has a tendency of energy transfer through the aqueous medium being treated. When treating wastewater, plasma is generated as a result of high-voltage discharge that is generated by the current electrical and magnetic field. The electromagnetic field is capable of sterilizing wastewater and therefore plasma technology is considered to be more effective in treating wastewater (Cheng et al. 2007).

\subsection{Ultrasound}

Great attention to research on the use of ultrasound in environmental protection is directed to the exploitation of the cavitation effect on the destruction of chemical and biological substances in wastewater as an example of an advanced oxidation process (Mason \& Tiehm 2001).

Ultrasonic waves are mechanical vibrations that spread through a medium that contains elastic properties such as solid, liquid or gas. The effect of ultrasound treatment is basically the result of ultrasonic induced cavitation by using sound wave in the lower frequency range. It is mainly applied in the range of $20-40 \mathrm{kHz}$, but there is an increasing interest for the effects of higher frequencies, but not above the $\mathrm{MHz}$ frequency where cavitation is difficult to achieve without the use of high power (Mason \& Lorimer 2002). Ultrasound has more and more potential for wastewater treatment. The use of sonochemical oxidation, which results in cavitation or formation of growth, and subsequent breakdown of bubbles or cavities created in an extremely small time interval (microseconds) and the release of large amounts of energy. Under these conditions, the organic compounds are dissociated directly by pyrolytic cleavage. On the other hand, the hydroxyl radicals formed by pyrolysis also participate in the degradation of organic substances (Babuponnusami \& Muthukumar 2013).

\subsection{UV radiation}

UV radiation is a part of electromagnetic radiation wavelengths of $100-400 \mathrm{~nm}$, which due to the release of large amounts of energy, effectively cleaves the chemical bonds within the molecules.

The photochemical processes of degradation are increasingly attributed to the importance of wastewater because chemical reactions are characterized by the formation of free radicals that can be easily produced by UV radiation (Mazzarino et al. 1999). Molecules absorb the energy of UV radiation and move to an excited state, but in such a state they remain very short and return to their ground state or break down to the radical. The resulting radicals are reactive and react with organic substances in reactions where the final products are of low molecular weight.

Research has shown that UV radiation at $253.7 \mathrm{~nm}$ wavelength (UV-C) efficiently breaks down industrial chemicals, hydrocarbons, fuel, dye and odour molecules. Also, ultraviolet radiation processing has proven to be effective when used as a pre-treatment or in combination with other processing technologies such as adsorption on activated carbon, biodegradation, ion exchange and membrane bioreactor treatment. 


\section{MATERIAL AND METHODS}

Wastewater from the production of olive oil (OMWW) was supplied from an oil mill in Northern Dalmatia and stored in plastic containers in a freezer at $-18{ }^{\circ} \mathrm{C}$. Before the treatment, to remove agglomerated particles, OMWW was tempered to room temperature and filtered through a $0.45 \mu \mathrm{m}$ pore paper filter. The treated OMWW had the following physico-chemical characteristics: $\mathrm{pH} 5.04$, electrical conductivity $872 \mu \mathrm{Scm}^{-1}$ and $29.8 \%$ saturation.

\subsection{Methods}

Physical characteristics of OMWW were measured in samples before and after treatment using a digital meter (HANNA instruments, Woonsocket, USA), $\mathrm{pH}$ value with $\mathrm{pH}$ electrode (HI11310), electrical conductivity with the electrode (HI763100) and oxygen saturation with the electrode (HI764080).

Pulse high-voltage generator (Spellman, UK) of $1200 \mathrm{~W}$ output power was used to generate plasma. A generator is connected to the circuit with resistors $9.5 \mathrm{M} \Omega$ and capacitor with capacity $0.75 \mathrm{nF}$. Plasma frequencies used for treatment were $60 \mathrm{~Hz}$ and $120 \mathrm{~Hz}$ and the voltage was measured by the Tektronix P6015A voltage-probe connected to the oscilloscope (Hantek DS05202BM, China).

A hybrid plasma reactor is a glass reactor with a total volume of $500 \mathrm{~mL}$ (working volume of $200 \mathrm{~mL}$ ), with rubber caps and adapted opening for the electrodes and gas injection (Figure 2). During treatment through highvoltage electrode (stainless steel needle Microlance TM $3.81 \mathrm{~cm}$ ) located at the bottom of the reactor and placed in the liquid phase, gases were blown $\mathrm{N}_{2}\left(\right.$ flow $\left.=4 \mathrm{Lmin}^{-1}\right), \mathrm{O}_{2}\left(\right.$ flow $\left.=6 \mathrm{Lmin}^{-1}\right)$ or air $\left(\right.$ flow $\left.=6 \mathrm{Lmin}^{-1}\right)$, which also enabled mixing of the sample. A ground electrode was placed on the upper side of the reactor, in the gas phase. This type of reactor enables discharge on the top of the electrode in the liquid and on the surface, where it discharges through the bubbles on the surface.

Table 1. Cold plasma treated samples

\begin{tabular}{|c|c|c|c|}
\hline Sample & \multicolumn{2}{|c|}{ Treatment } & $t(\min )$ \\
\hline $\mathbf{A}$ & \multicolumn{2}{|c|}{ untreated } & 0 \\
\hline B & \multirow{3}{*}{$60 \mathrm{~Hz}$} & $\mathrm{~N}_{2}$ & 30 \\
\hline $\mathbf{C}$ & & air & 30 \\
\hline D & & $\mathrm{O}_{2}$ & 30 \\
\hline $\mathbf{E}$ & \multirow{3}{*}{$120 \mathrm{~Hz}$} & $\mathrm{~N}_{2}$ & 30 \\
\hline $\mathbf{F}$ & & air & 30 \\
\hline $\mathbf{G}$ & & $\mathrm{O}_{2}$ & 30 \\
\hline $\mathbf{H}$ & \multicolumn{2}{|c|}{ untreated $+\mathrm{FeCl}_{3} \times 6 \mathrm{H}_{2} \mathrm{O}$} & 30 \\
\hline I & \multirow{3}{*}{$60 \mathrm{~Hz}$} & $\mathrm{~N}_{2}+\mathrm{FeCl}_{3} \times 6 \mathrm{H}_{2} \mathrm{O}$ & 30 \\
\hline $\mathbf{J}$ & & air $+\mathrm{FeCl}_{3} \times 6 \mathrm{H}_{2} \mathrm{O}$ & 30 \\
\hline $\mathbf{K}$ & & $\mathrm{O}_{2}+\mathrm{FeCl}_{3} \times 6 \mathrm{H}_{2} \mathrm{O}$ & 30 \\
\hline $\mathbf{L}$ & \multirow{3}{*}{$120 \mathrm{~Hz}$} & $\mathrm{~N}_{2}+\mathrm{FeCl}_{3} \times 6 \mathrm{H}_{2} \mathrm{O}$ & 30 \\
\hline $\mathbf{M}$ & & air $+\mathrm{FeCl}_{3} \times 6 \mathrm{H}_{2} \mathrm{O}$ & 30 \\
\hline $\mathbf{N}$ & & $\mathrm{O}_{2}+\mathrm{FeCl}_{3} \times 6 \mathrm{H}_{2} \mathrm{O}$ & 30 \\
\hline
\end{tabular}

In UV radiation treatment was used UV-C lamp of $16 \mathrm{~W}$ power placed in stainless steel tube (Spa Dealers Lux Style, Finland). The peristaltic pump (SP 311 VELP Scientifica, Italy) provided a constant circulation of wastewater from the reactor through UV lamp.

In order to have most effective further wastewater treatment, chemical requirements were decreased by up to $70 \%$. OMWW samples of $200 \mathrm{~mL}$ volume were treated for 30 minutes with the previous addition of: $51.5 \mu \mathrm{L}$ $\mathrm{H}_{2} \mathrm{O}_{2}\left(\mathrm{c}=1 \mathrm{gL}^{-1}\right), 0.2 \mathrm{~g} \mathrm{TiO}_{2}\left(\mathrm{c}=1 \mathrm{gL}^{-1}\right)$ and $33 \mu \mathrm{L}$ of $\mathrm{FeCl}_{3} \times 6 \mathrm{H}_{2} \mathrm{O}\left(\mathrm{c}=1 \mathrm{molL}^{-1}\right)$.

Table 2. UV radiation treated samples

\begin{tabular}{|c|c|c|}
\hline Sample & Treatment & t (min) \\
\hline $\mathbf{1 .}$ & $\mathrm{H}_{2} \mathrm{O}_{2} / \mathrm{UV}$ & 30 \\
\hline $\mathbf{2 .}$ & $\mathrm{TiO}_{2} / \mathrm{UV}$ & 30 \\
\hline $\mathbf{3 .}$ & $\mathrm{FeCl}_{3} \times 6 \mathrm{H}_{2} \mathrm{O} / \mathrm{UV}$ & 30 \\
\hline $\mathbf{4}$. & $\mathrm{H}_{2} \mathrm{O}_{2}+\mathrm{FeCl}_{3} \times 6 \mathrm{H}_{2} \mathrm{O} / \mathrm{UV}$ & 30 \\
\hline
\end{tabular}

The ultrasonic processor - Misonix Sonicators S-4000 (Connecticut, USA) was used to generate high intensity ultrasound for ultrasonic treatment. The device has a maximum power of $600 \mathrm{~W}$, a voltage of $120-240$ $\mathrm{V}$ and a frequency of $20 \mathrm{kHz}$. The thermocouple was immersed in the sample during the entire treatment and connected to an ultrasonic processor. In the study was used an ultrasound probe of $12.7 \mathrm{~mm}$ diameter. Ultrasonic power loss occurs by passing through the medium due to heat development and because of it treatment time was 
limited to 10 minutes without cooling the reactor chamber. OMWW volumes of $200 \mathrm{ml}$ were treated for 10 minutes with the previous addition of: $51.5 \mu \mathrm{L} \mathrm{H}_{2} \mathrm{O}_{2}\left(\mathrm{c}=1 \mathrm{gL}^{-1}\right), 0.2 \mathrm{~g} \mathrm{TiO} 2\left(\mathrm{c}=1 \mathrm{gL}^{-1}\right)$ and $33 \mu \mathrm{L} \mathrm{FeCl}_{3} \mathrm{x}$ $6 \mathrm{H}_{2} \mathrm{O}\left(\mathrm{c}=1 \mathrm{molL}^{-1}\right)$.

Table 3. Ultrasound treated samples

\begin{tabular}{|c|c|c|}
\hline Sample & Treatment & t (min) \\
\hline $\mathbf{5 .}$ & $\mathrm{H}_{2} \mathrm{O}_{2} /$ US & 10 \\
\hline $\mathbf{6 .}$ & $\mathrm{TiO}_{2} / \mathrm{US}$ & 10 \\
\hline $\mathbf{7 .}$ & $\mathrm{FeCl}_{3} \times 6 \mathrm{H}_{2} \mathrm{O} / \mathrm{US}$ & 10 \\
\hline $\mathbf{8 .}$ & $\mathrm{H}_{2} \mathrm{O}_{2}+\mathrm{FeCl}_{3} \times 6 \mathrm{H}_{2} \mathrm{O} / \mathrm{US}$ & 10 \\
\hline
\end{tabular}

Determination of sample colour was tested on Specord 50 Plus Spectrophotometer (AnalytikJena, Jena, Germany) with measurements of L*, a* and $b^{*}$ values on the $10 \mathrm{~mm}$ mesh mask. Coordinates of the CIE Lab colour system are based on Hering's theory of opposite colour pairs representing the system's axis. The chromatographic characteristics of the wastewater according to the CIE system are described by the following parameters: achromatic axis L* (lightness) indicates luminance in the range of $0 \%$ to $100 \%$, with $0 \%$ black and $100 \%$ white; axis $\mathrm{a}^{*}$ represents the range of colours red-green and axis $\mathrm{b}^{*}$ range of colours yellow-blue (Mohammadi et al. 2008; Sharma \& Rodríguez-Pardo 2012; de Mendonça et al. 2016). All measurements were performed in SCI (Specular Component Included) mode.

Samples are defrosted and stored at room temperature prior to colour determination. The transmittance measurement was carried out in plastic cuvette at wavelengths of 380 to $780 \mathrm{~nm}$, each $5 \mathrm{~nm}$, with the D65 illuminator and the viewing angle of $10^{\circ}$ versus distilled water as a blank probe. The tested sample $\mathrm{L}^{*}, \mathrm{a}^{*}, \mathrm{~b}^{*}, \mathrm{C}$ and $\mathrm{h}$ values are calculated with automatic data processing using CIE Lab software support. It expresses colour as three values: $\mathrm{L}^{*}$ for the lightness from black (0) to white $(100), \mathrm{a}^{*}$ from green $(-)$ to red $(+)$, and $\mathrm{b}^{*}$ from blue $(-)$ to yellow $(+)$. Based on the measured parameters $L^{*}, a^{*}$ and $b^{*}$ values, the total colour change $\Delta \mathrm{E}$ is calculated according to Equation 1:

$$
\Delta E *=\sqrt{ }\left(L *-L_{r e f} *\right)^{2}+\left(a *-a_{r e f} *\right)^{2}+\left(b *-b_{r e f} *\right)^{2}
$$

$L^{*}$ - the colour brightness of the examined sample in the $\mathrm{L}^{*} \mathrm{a}^{*} \mathrm{~b}^{*}$ system

$a^{*}$ - colour parameter of the examined sample

$b^{*}$ - colour parameter of the examined sample

$L_{r e f}{ }^{*}$ - the colour brightness of the reference sample

$a_{r e f} *$ - colour parameter of the reference sample

$b_{r e f} *$ - colour parameter of the reference sample

Dissolved Organic Carbon (DOC) was measured on the TOC Analyser (TOC-VCPH, Shimadzu, Japan) by the (NPOC) non-purgeable organic carbon method. The combustion catalytic oxidation method achieves total combustion of samples by heating them to $680^{\circ} \mathrm{C}$ in an oxygen-rich environment inside $\mathrm{TC}$ combustion tubes filled with a platinum catalyst. Since simple oxidation principles are used through heating and combustion, pretreatment and post-treatment are not required. Carbon dioxide generated by oxidation is detected by an infrared gas analyser (NDIR). By adopting the newly designed highly sensitive NDIR, the TOC-L series achieves high detection susceptibility with a detection limit of $4 \mu \mathrm{gL}^{-1}$, the highest level for the catalytic combustion oxidation method.

The DOC and TOC determination method requires the removal of all inorganic carbons from the sample before the sample is analysed for the organic carbon content. If inorganic carbon is not completely removed, there will be a significant error. Inorganic carbon disturbance is removed by converting inorganic carbon into $\mathrm{CO} 2$ by acidification of the sample at $\mathrm{pH} 2-3$ and sifting inert gas to remove the generated $\mathrm{CO} 2$. The sample is then injected into the instrumental TOC system and the organic carbon is oxidized to $\mathrm{CO} 2$ released from the sample and detected as DOC or TOC (Shimadzu 2018).

The OMWW content of DOC depends significantly on the raw material, climatic conditions and operating conditions of the plant. Because of the presence of suspended material, TOC and DOC significantly differ and therefore can be expected results variability.

\section{RESULTS AND DISCUSSION}

\subsection{Physico-chemical characteristics}

In the treated samples, the physical characteristics of $\mathrm{pH}$ value, electrical conductivity and oxygen saturation were measured and the following results were obtained. In the treated samples a decrease in the $\mathrm{pH}$ value was 
observed after cold plasma treatment, especially in treatment with $\mathrm{FeCl}_{3} \times 6 \mathrm{H}_{2} \mathrm{O}$ supplementation. The pH elevation was observed in UV radiation treatment while ultrasonic treatment did not change $\mathrm{pH}$ value.

The difference in $\mathrm{pH}$ value of the treated samples is due to the different effect of the individual treatments. Acidification of the solution in plasma treatment can be explained by the partial oxidation of the phenolic compounds into low molecular weight carboxylic acids, which predominantly occurs within the first stage of the Fenton process (Esteves et al. 2018). In contrast, UV radiation treatment raises the $\mathrm{pH}$ due to the influence of different ions on the absorption of UV light and the reaction of undesirable substances with hydroxyl radicals.

Different values of $\mathrm{pH}$ and conductivity after the ultrasound treatment can be explained on the basis of the main factors limiting acoustic cavitation like degassing of liquid, high atmospheric pressure, temperature elevation, and irradiation with increasing US frequencies (Herrmann 1999).

Due to the development of high temperatures during ultrasound processing $\left(>60^{\circ} \mathrm{C}\right)$, the treatment time was $3 x$ shorter, compared to UV treatment. Ultrasound leads to the formation, growth and breakdown of the bubble, which is followed by the generation of very high local temperature. In the range of 20 to $80^{\circ} \mathrm{C}$, the temperaturedependent degradation is weak, but cooling is recommended for temperatures above $80{ }^{\circ} \mathrm{C}$ due to a drastic decrease in activity and reaction rate (Herrmann 1999).

After treatment in a hybrid plasma reactor, values of electrical conductivity have increased as well as in ultrasonic treatment with $\mathrm{H}_{2} \mathrm{O}_{2}$ supplementation, whereas in the UV and US treatments there is usually a decrease in electrical conductivity. The agglomerates present in the OMWW are degraded by the cold plasma treatment and contribute to the increase of electrical conductivity. Also, nitrate and nitric products dissolving in water during plasma treatment can induce a steep $\mathrm{pH}$ lowering of the solution and an increasing of conductivity as well as participate in various reactions (Jiang et.al. 2014). Oxygen saturation increases after treatments where air or oxygen was blown into samples, while in samples where nitrogen was blown oxygen saturation decreased.

\subsection{Colour intensity}

OMWW treatments in a hybrid plasma reactor with selected process sizes and using UV radiation and/or US treatments gave the following results. Using the colourimetric method prior to treatment (Figure 1) and after treatment (Figure 2), the colouring intensity decreased. The most significant colour change occurred in samples treated with cold plasma with nitrogen and air blow at a frequency of $120 \mathrm{~Hz}$ with addition of $\mathrm{FeCl}_{3} \times 6 \mathrm{H}_{2} \mathrm{O}$, whereas colour change in treated US and/or UV radiation is most pronounced in samples in which $\mathrm{H}_{2} \mathrm{O}_{2}$ was added.

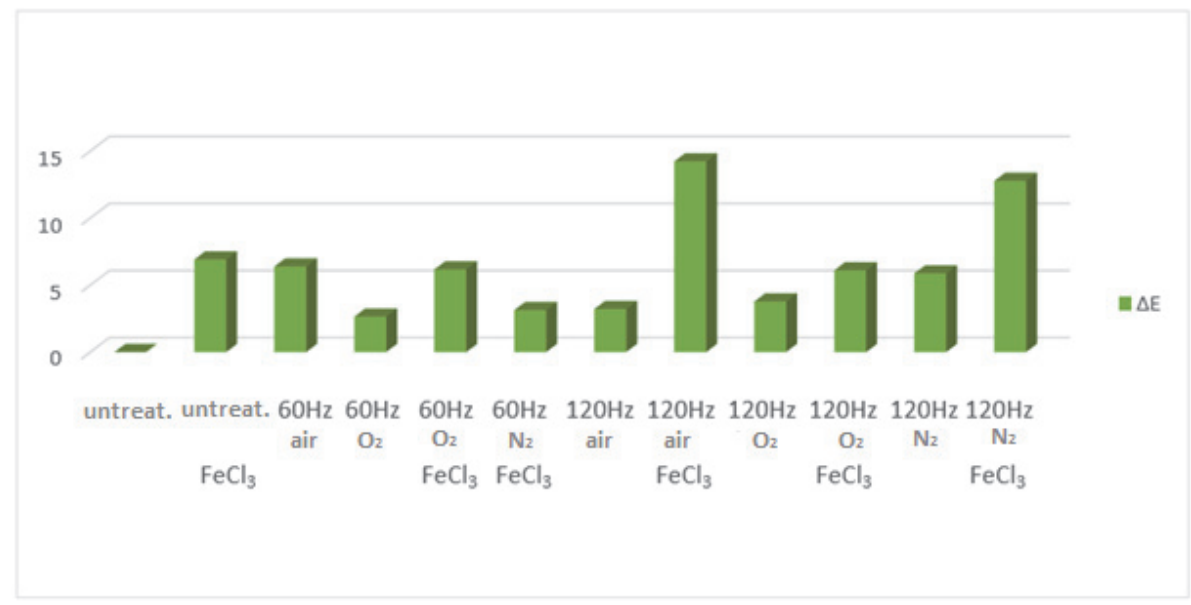

Figure 1. Colour change in samples treated with cold plasma

In the samples to which Fenton's method was applied, the colour change is more significant in cold plasma treated samples, while in US and/or UV treated samples, the colour change is lower. The reason for this is that the efficiency of the Fenton process is affected by the amount of added iron ion, the concentration of $\mathrm{H}_{2} \mathrm{O}_{2}$, the concentration of contaminated substances and $\mathrm{pH}$. At $\mathrm{pH}$ values above $4, \mathrm{Fe}^{2+}$ ions are highly unstable and easily transfer to a more stable $\mathrm{Fe}^{3+}$ ion that creates complexes with a hydroxyl ion (Niaounakis \& Halvadakis 2006). $\mathrm{pH}$ values of cold plasma treated samples ranged between 3.34 and 5.05 while $\mathrm{pH}$ in samples treated with US and/or UV radiation ranged between 5.01 and 5.76, which influenced the efficacy of Fenton's method. 


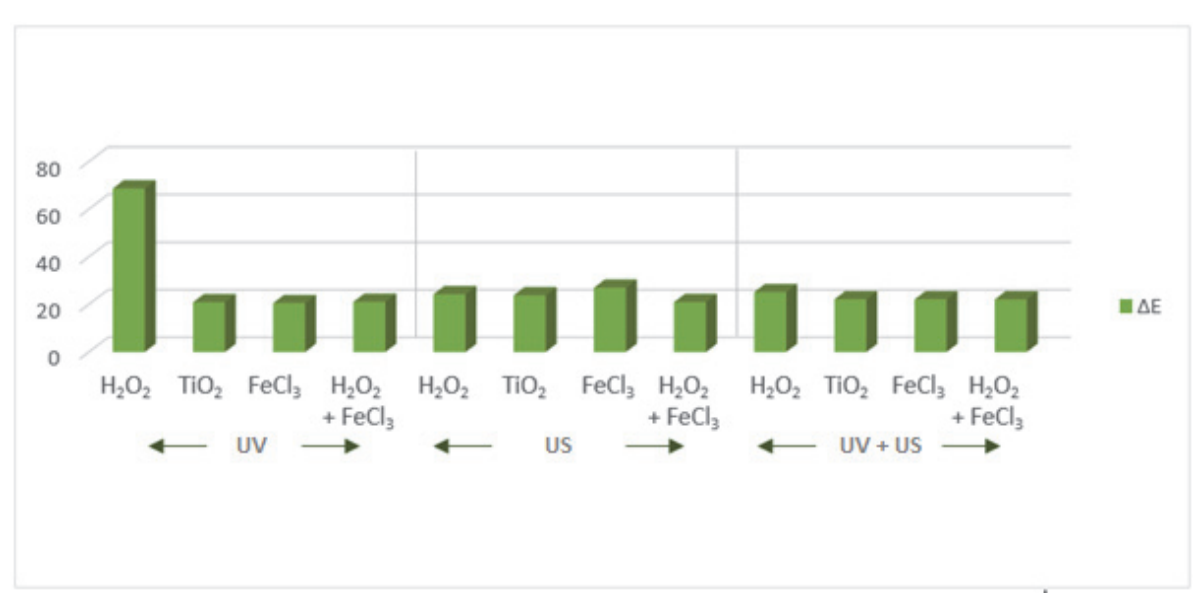

Figure 2. Colour change in samples treated with US and/or UV radiation

Since the photooxidation process is very limited, ultraviolet light is used in combination with a strong oxidant such as $\mathrm{H}_{2} \mathrm{O}_{2}$ or $\mathrm{TiO}_{2}$ catalyst. (Daneshvar et al. 2008). According to the results of the research, Rezaee et al. (2008), under the optimal dose of $\mathrm{H}_{2} \mathrm{O}_{2}\left(2.5 \mathrm{mmolL}^{-1}\right)$ and $\mathrm{UV}$ radiation $(55 \mathrm{~W})$ for less than 30 minutes, the solution was fully decolourized. The percentage of decolourization is linearly increased by UV radiation and the nonlinear increase of the initial concentration of $\mathrm{H}_{2} \mathrm{O}_{2}$. According to this research, the best result of ultrasonic removal and/or ultraviolet radiation is achieved by UV treatment with the addition of $\mathrm{H}_{2} \mathrm{O}_{2}$.

\subsection{Colour intensity}

Figure 3 presents the concentrations of total dissolved carbon in samples after treatment in a hybrid plasma reactor at selected process conditions. From the obtained values is apparent that in relation to the DOC value in the untreated sample, the highest reduction in DOC was obtained in the sample treated with cold plasma at a frequency of $60 \mathrm{~Hz}$ with nitrogen and addition of $\mathrm{FeCl}_{3} \times 6 \mathrm{H}_{2} \mathrm{O}$.

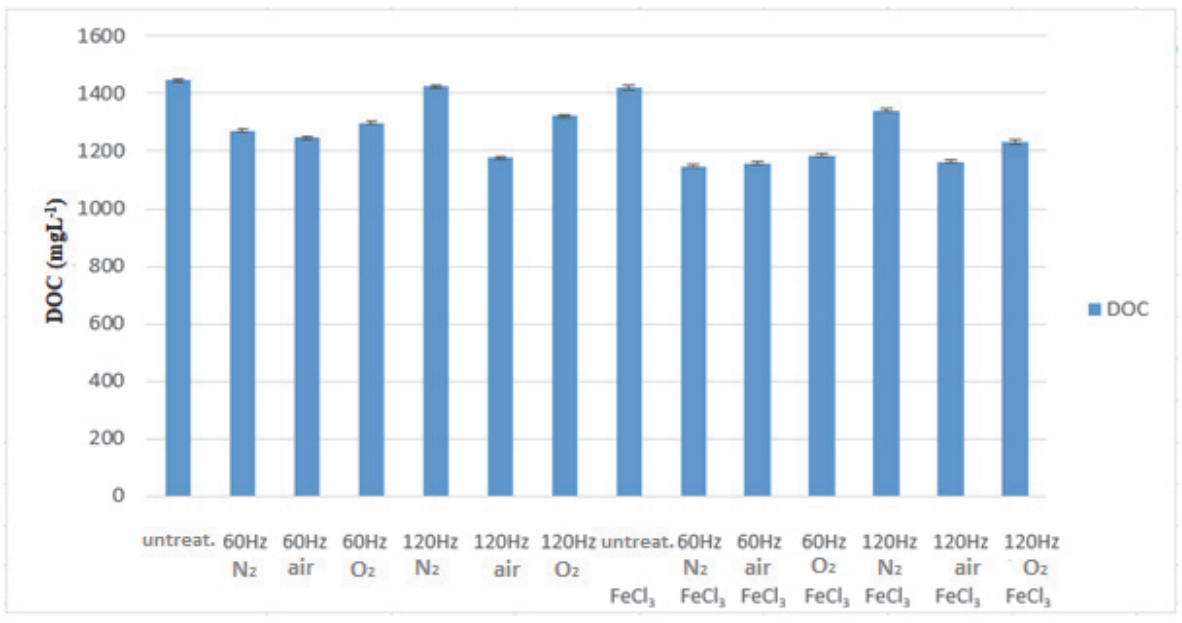

Figure 3. DOC values in samples after cold plasma treatment

The values of total dissolved carbon in the samples treated with ultrasound and/or UV radiation with the previous addition of $\mathrm{H}_{2} \mathrm{O}_{2}, \mathrm{TiO}_{2}$ and $\mathrm{FeCl}_{3} \times 6 \mathrm{H}_{2} \mathrm{O}$ with the selected process conditions are shown in Figure 4. It is apparent that the highest value of total dissolved carbon $\left(2546 \mathrm{mgL}^{-1}\right)$ is obtained by ultrasonic and UV radiation treatment with the prior addition of $30 \% \mathrm{H}_{2} \mathrm{O}_{2}$ in a volume of $51 \mu \mathrm{L}$. The disadvantage of this combination is that $\mathrm{H}_{2} \mathrm{O}_{2}$ has a poor absorption of $\mathrm{UV}$ radiation and most of the light input in wastewater treatment will be wasted (Crittenden et al. 2005). 


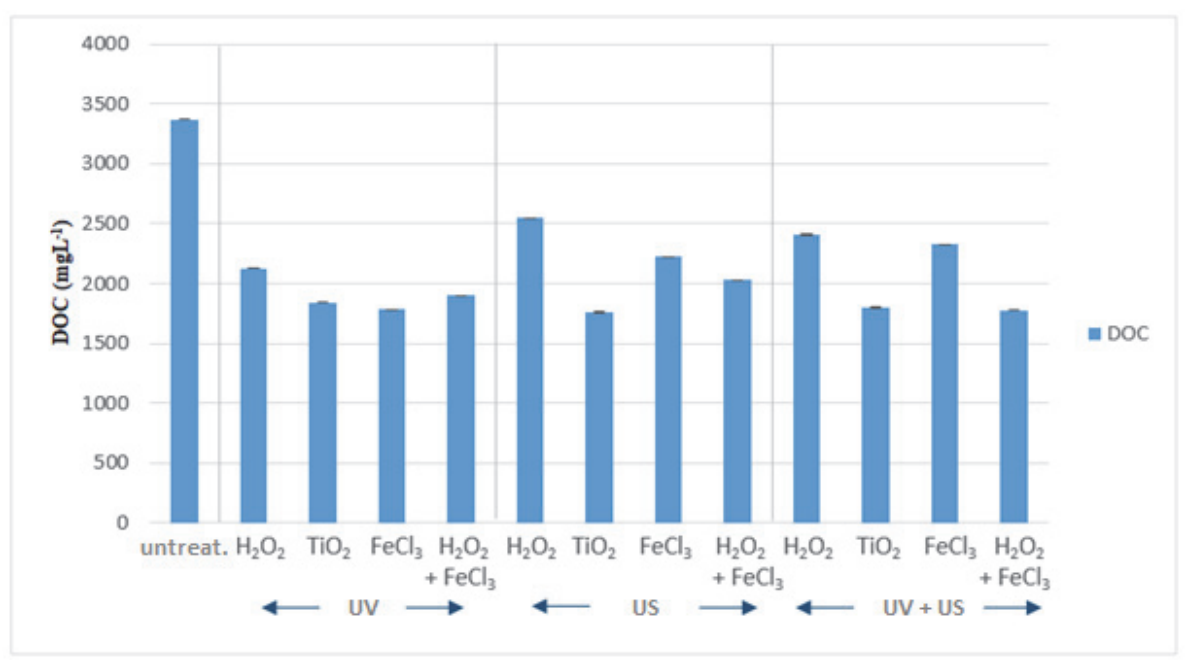

Figure 4. DOC values in samples after UV and/or US treatment

The combination of $\mathrm{H}_{2} \mathrm{O}_{2}$ and UV radiation with the Fenton reagent proved to be very effective in reducing the DOC value to $1897 \mathrm{mgL}^{-1}$. Compared to the combination of UV radiation, $\mathrm{H}_{2} \mathrm{O}_{2}$ and Fenton reagent with the Fenton reagent itself, the combination produces more hydroxyl radicals and thus increases the rate of degradation of organic contamination. The required amount of iron salt for treatment is considerably lower in the combination of US/UV compared to the Fenton method itself where the iron ions have to be added at regular intervals for the reaction to flow.

Furthermore, the addition of $0.2 \mathrm{~g}$ of $\mathrm{TiO}_{2}$ with ultrasound and $\mathrm{UV}$ treatment have caused the most significant change in the DOC value. Wastewater treatment with $\mathrm{TiO}_{2}$ and $\mathrm{UV}$ radiation has been intensively used in wastewater treatment since $\mathrm{TiO}_{2}$ is cheap and highly available chemical, biologically inert and stable, capable of oxidizing organic compounds into harmless compounds such as $\mathrm{H}_{2} \mathrm{O}$ and $\mathrm{CO}_{2}$. El-Hajjouji et al. (2008), in their research, investigated the effect of $1 \mathrm{gL}^{-1} \mathrm{TiO}_{2}$ and $\mathrm{UV}$ radiation on wastewater from olive oil production. After 24 hours, $22 \%$ COD and $94 \%$ phenol were removed. Almost $30 \%$ of DOC was removed in the presence of 0.5 and $1 \mathrm{gL}^{-1} \mathrm{TiO}_{2}$ over a period of 50-60 minutes.

Figure 3 and Figure 4 present a significant difference in total dissolved carbon values. After cold plasma treatment values of DOC ranges from $1148 \mathrm{mgL}^{-1}$ to $1421 \mathrm{mgL}^{-1}$, which is a significant reduction compared to the untreated sample. The DOC values after ultrasound and UV radiation treatment are in the range of 1761 $\mathrm{mgL}^{-1}$ to $2409 \mathrm{mgL}^{-1}$.

\section{CONCLUSION}

After the research conducted, it can be concluded that the most significant colour changes, as well as the greatest reduction of total dissolved carbon, are in samples treated with cold plasma and in samples with the addition of Fenton reagent. After 30 minutes of UV treatment, 10 minutes by ultrasound or combination of US and UV radiation for 10 minutes, the biggest colour change was observed by applying the combination of UV treatment with the addition of strong oxidants $\mathrm{H}_{2} \mathrm{O}_{2}$ and the catalyst. The value of total dissolved carbon was almost double reduced by ultrasound treatment with the addition of $\mathrm{TiO}_{2}$ catalyst in comparison to the untreated sample.

Observing the influence of all conducted treatments, advanced oxidation treatments has proved to be effective treatments for olive mill wastewater and it is useful to conduct further extensive research for possible effective industrial applications in the future.

\section{REFERENCES}

Adewuyi YG (2001) Sonochemistry: environmental science and engineering applications. Ind Eng Chem Res 40(22):4681-4715

Akar T, Tosun I, Kaynak Z, Ozkara E, Yeni O, Sahin EN, Akar ST (2009) An attractive agro-industrial byproduct in environmental cleanup: Dye biosorption potential of untreated olive pomance, J Hazard Mater 166:1217-1225

Babuponnusami A, Muthukumar K (2013) A review on Fenton and improvements to the Fenton process for wastewater treatmen T J Environ Chem Eng 2:557-572

Bhatkhande DS, Pangarkar VG, Beenackers AACM (2002) Photocatalytic degradation for environmental applications: a review. J Chem Technol Biotechnol 77(1):102-116 
Cheng H, Chen S, Wo Y, Ho D (2007) Non-thermal plasma technology for degradation of organic compounds in wastewater control: a critical review. J Environ Eng Manage 17(6):427-433

Crittenden JC, Trussell RR, Hand DW, Howe KJ, Tchobanoglous G (2005) Water treatment: Principles and Design. 2 ed., Wiley, New Jersey

Daneshvar N, Aber S, Hosseinzadeh F (2008) Study of C.I. acid orange 7 removal in contaminated water by photo oxidation processes. Global NEST Journal, 10:16-23

De Mendonça KS, Corrêa JLG, de Jesus Junqueira JR, Cirillo MR, Figueira FV, Nunes Carvalho EE (2017) Influences of convective and vacuum drying on the quality attributes of osmo-dried pequi. Food Chem 224:212218

El-Hajjouji H, Barje F, Pinelli E, Baily JR, Richard C, Winterton P, Revel JC, Hafidi M (2008) Photochemical UV/TiO 2 treatment of olive mill wastewater (OMW). Bioresour Technol 99:7264-7269

Esteves MB, Rodrigues CSD, Madeira LM (2018) Synthetic olive mill wastewater treatment by Fenton's process in batch and continuous reactors operation. Environ Sci Pollut Res 25:34826-34838

Gogate PR, Pandit AB (2004) A review of imperative technologies for wastewater treatment I: oxidation technologies at ambient conditions. Adv Environ Res 8:501-551

Herrmann JM (1999) Heterogeneous photocatalysis: fundamentals and applications to theremoval of various types of aqueous pollutants. Catal Today 53:115-129

Jiang B, Zheng J, Qui S, Wu M, Zhang Q, Yan Z, Xue Q (2014) Review on electrical discharge plasma technology for wastewater remediation. Chem Eng J 236:348-368

Kallel M, Belaid C, Boussahel R, Ksibi M, Montiel A, Elleuch B (2009) Olive mill wastewater degradation by Fenton oxidation with zero-valent iron and hydrogen peroxide. J Hazard Mater 163(2-3):550-554

Li J, Zhou ZG, Wang HJ, Li GF, Wu Y (2007) Research on the decolouration of dye wastewater by combi nation of pulsed discharge plasma and $\mathrm{TiO}_{2}$, nanoparticles. Desalination 212(1-3):123-128

Mason TJ, Phillip Lorimer J (2002) Applied sonochemistry: the uses of power ultrasound in chemistry and processing. Wiley-VCH.

Mason TJ, Tiehm A (2001) Advances in Sonochemistry: Ultrasound in Environmental. JAI Press.

Mazzarino I, Piccinini P, Spinelli L (1999) Degradation of organic pollutants by photochemical reactors. Catal Today 48(1-4):315-321

Mohammadi A, Rafiee S, Emam-Djomeh Z, Keyhani A (2008) Kinetic Models for Colour Changes in Kiwifruit Slices During Hot Air Drying. World J Agric Sci 4(3):376-383

Morillo JA, Antizar-Ladislao B, Monteoliva-Sanchez M, Ramos-Cormenzana A, Russell NJ (2009) Bioremediation and biovalorisation of olive-mill wastes, Appl Microbiol Biotechnol 82:25-39

Mott-Smith H Jr, Langmuir I (1926) The theory of collectors in gaseous discharges, Phys Rev 28:727-763

Nesheiwat FK, Swanson AG (2000) Clean contaminated sites using Fenton's reagent. Chem Eng Prog 96(4):61-66

Niaounakis M, Halvadakis CP (2006) Olive processing waste management - Literature review and patent survey. 2nd ed., Elsevier, Amsterdam

Paredes C, Cegarra J, Roig A, Sanchez-Monedero MA, Bernal MP (1997) Characterization of olive-mill wastewater (alpechin) and its sludge for agricultural purposes, Bioresurce Technol 67:111-115

Quaratino D, D’Annibale A, Federici F, Cereti CF, Rossini F, Fenice M (2007) Enzyme and fungal treatments and a combination thereof reduce olive mill wastewater phytotoxicity on Zea mays L. seeds. Chemosphere 66:1627-1633

Rezaee A, Ghaneian MT, Hashemian SJ, Moussavi G, Khavanin A, Ghanizadeh G (2008) Decolourization of Reactive Blue 19 Dye from Textile Wastewater by the $\mathrm{UV} / \mathrm{H}_{2} \mathrm{O}_{2}$ Process J Appl Sci, 8(6):1108-1112

Roya A, Hosseini H (2014) Non-thermal plasma as a new food preservation method, Its present and future prospect. J Paramed Sci 5:1-5

Sharma G, Rodríguez-Pardo CE (2012) The Dark Side of CIELAB, Available via DIALOG. https://www.researchgate.net/publication/228518447 The dark side of CIELAB Cited July 19, 2018.

Shimadzu (2018) TOC (total organic carbon) Measurement. Available via DIALOG. https:/www.shimadzu.com/an/toc/lab/toc-14.html Cited July 19, 2018.

Thirumdas R, Sarangapani C, Annapure US (2014) Cold Plasma: A novel non-thermal technology for food processing. Food Biopysics 10(1):1-11

Tsagaraki E, Lazarides HN, Petrotos KB (2007) Olive Mill Wastewater Treatment. In: Oreopoulou V, Russ W (eds.) Utilization of By-Products and Treatment of Waste in the Food Industry. New York: Springer.

Zaviska F, Drogui P, Mercier G, Blais JF (2009) Procédés d'oxydation avancée dans le traitement des eaux et des effluents industriels: Application à la dégradation des polluants réfractaires. Rev Sci Eau 22(4):535-564 